\title{
Binary Mixture of Tri-Octyl Amine and Cyanex 923 as Extractant for the Extraction of Zr (IV) from Acidic Chloride Medium
}

\author{
Bhikari Charan Bhatta ${ }^{1}$, Sujata Mishra ${ }^{2 *}$ \\ ${ }^{1}$ Department of Chemistry, College of Engineering and Technology, Bhubaneswar, Odisha \\ ${ }^{2}$ Department of Chemistry, Institute of Technical Education and Research, Siksha ' $O$ ' Anusandhan Deemed to \\ be University, Bhubaneswar, Odisha, India \\ Email: ${ }^{\text {drsujatamishra97@gmail.com }}$
}

Received 23 January 2014; revised 23 February 2014; accepted 28 February 2014

Copyright (C) 2014 by authors and Scientific Research Publishing Inc.

This work is licensed under the Creative Commons Attribution International License (CC BY).

http://creativecommons.org/licenses/by/4.0/

(c) (i) Open Access

\begin{abstract}
The extraction of zirconium (IV) from aqueous HCl solution by binary mixture TOA and Cyanex 923 using kerosene as diluent was studied. The effect of parameters like aqueous phase acid concentration, extractant concentration, chloride ion concentration, diverse ion effect, metal loading, nature of diluents and temperature on the extraction of $\mathrm{Zr}$ (IV) was investigated. The percentage of extraction of Zr(IV) became 100\% with $0.1 \mathrm{M}$ TOA and $0.01 \mathrm{M}$ Cyanex 923 from $7 \mathrm{M} \mathrm{HCl}$ and also from $4 \mathrm{M} \mathrm{HCl}$ with 0.1 M TOA and 0.02 M Cyanex 923. Benzene was found to be effective diluent for the extraction of $\mathrm{Zr}$ (IV) with binary mixture of TOA and Cyanex 923. The positive enthalpy change and positive entropy change in the binary extraction system show endothermic process with increase in randomness. Stripping of $\mathrm{Zr}$ (IV) from the loaded organic phase containing mixture of TOA (0.1 M) and Cyanex $923(0.01 \mathrm{M})$ indicated that $\mathrm{HNO}_{3}$ and $\mathrm{Na}_{2} \mathrm{CO}_{3}$ are the best stripping agents.
\end{abstract}

\section{Keywords}

Zirconium, Solvent Extraction, Hydrochloric Acid, TOA, Cyanex 923, Kerosene

\section{Introduction}

Zirconium metal is highly desirable as a cladding material for nuclear fuel rods in nuclear power plants, because of its very low absorption cross-section for neutrons [1]. Zircon, the primary ore is used as a nuclear grade mate-

*Corresponding author.

How to cite this paper: Bhatta, B.C. and Mishra, S. (2014) Binary Mixture of Tri-Octyl Amine and Cyanex 923 as Extractant for the Extraction of Zr (IV) from Acidic Chloride Medium. International Journal of Nonferrous Metallurgy, 3, 9-17. 
rial. High molecular weight alkyl amines (tertiary and quaternary amines) have a wide variety of uses in the mining industry for the purification and recovery of various metal species by means of solvent extraction. Extraction of zirconium using liquid anion exchanges has been reported by several workers [2]-[6]. Solvent extraction of $\mathrm{Zr}(\mathrm{IV})$ was carried out at $5^{\circ}, 25^{\circ}$ and $40^{\circ} \mathrm{C}$ using Amberlite LA-2, TBP and HDEHP(di-2-ethylhexyl phosphoric acid) in toluene or kerosene from solutions of $\mathrm{HCl}, \mathrm{HBr}$ or $\mathrm{KI}$ [7]. Solvent extraction of $\mathrm{Zr}(\mathrm{IV})$ from acidic chloride solution has been carried out with PC-88A (2-ethylhexyl phosphonic acid mono-2-ethylhexyl ester) as the extarctant [8]. Higher acid concentration increases the extraction of zirconium and an increase of the extractant and chloride ion concentration at constant $\mathrm{H}^{+}$ion also increases the extraction. Extraction of $\mathrm{Zr}(\mathrm{IV})$ from acidic chloride solutions was carried out with Cyanex-272 as an extractant diluted in kerosene. An increase of the acid concentration lowers the percentage of extraction of metal which indicates that the extraction follows cation exchange mechanism [9]. The complex formation ability in $\mathrm{HCl}$ solution decreases from $\mathrm{Zr}$ to Rf independent of the $\mathrm{pH}$ of the medium. A decisive energetic factor in hydrolysis or complex formation process is proved to be a predominant electrostatic metal-ligand interaction [10]. The stoichiometric relation for the extraction of zirconium and hafnium from acid chloride solutions was investigated with Versatic Acid-10 by Lee et al. [11]. In order to produce high purity zirconium by removing iron using liquid-liquid extraction, several types of commercial extractants have been chosen, examined and compared by Chang et al. [12]. Synergistic extraction involving extraction of metal ion with binary mixture of extractants has been applied to increase the extractability. It was first reported by Blake et al. [13]. As a branch of solvent extraction, synergistic extraction has become a common method for the separation of metal ions. It not only improves the extraction efficiency and extraction selectivity but also enhances the stability of the extracted complexes, increasing the solubility of the extracted complexes in the organic phase, eliminating emulsification and the formation of the third phase, and in turn increases the extraction reaction rate [14]. Synergistic effect of neutral donors on the extraction of zirconium (IV) by salicylaldoxime in dichloromethane has been studied [15]. Extraction of zirconium (IV) from hydrochloric acid solution by tri-octylamine and neutral donors in carbon tetrachloride has been investigated by Biswas et al. [16] and they found that higher extraction takes place in case of mixture than by single extractant. The extraction of $\mathrm{Zr}(\mathrm{IV})$ from aqueous hydrochloric acid solution by TTA (2-thenoyltrifluoroacetone) is a slow process but the addition of neutral extractant, DPSO(di-n-pentyl sulfoxide) enhances considerably the rate as well as the percentage of extraction as reported by Reddy et al. [17]. According to Mishra et al. [18] the presence of thiocyanate ions results in appreciable extraction of $\mathrm{Zr}(\mathrm{IV})$ by Aliquat336 from low aqueous $\mathrm{HCl}$ acidities. The variation in concentration of $\mathrm{HCl}$, thiocyanate and Aliquat336 greatly influences the extent of extraction. Mixture of Aliquat336 and TOPO results in synergistic extraction of $\mathrm{Zr}$ and $\mathrm{Hf}$ from acidic thiocyanate media. Separation of zirconium and hafnium by solvent extraction using mixture of TBP and Cyanex 923 was studied by Taghizadeh et al. [19]. The present authors have already reported the study of extraction of $\mathrm{Zr}(\mathrm{IV})$ from $\mathrm{HCl}$ medium using binary mixture of TOA and Cyanex 921 in kerosene [20]. Tri-octylamine (TOA) $\left(\mathrm{R}_{3} \mathrm{~N}: \mathrm{R}=\mathrm{C}_{8} \mathrm{H}_{17}\right)$ is very selective in various separation processes and easily soluble in most organic diluents in a wide temperature range. Cyanex 923 is a liquid, cheaper extractant as compared to tri-n-butyl phosphate and has better radiolytic stability. There is no report on systematic investigations of extraction of $\mathrm{Zr}(\mathrm{IV})$ from $\mathrm{HCl}$ medium with binary mixture of TOA and Cyanex 923 in kerosene so far. Therefore, in the present study, an attempt has been made to know the effect of various parameters such as aqueous phase acid concentration, extractant molarity, chloride ion concentration, temperature, metal loading, diverse ion, nature of diluents on the extraction of $\mathrm{Zr}(\mathrm{IV})$ from $\mathrm{HCl}$ medium using binary mixture of TOA and Cyanex 923. Themodynamic parameters associated with the binary extraction system have also been determined. Nitric acid and Sodium carbonate have been used as the stripping agents for recovery of zirconium from loaded organic phase containing binary mixture of TOA and Cyanex 923 under conditions of maximum extraction.

\section{Experimental}

\subsection{Reagents}

The stock solution of $\mathrm{Zr}(\mathrm{IV})(0.01 \mathrm{M})$ was prepared by dissolving its oxychloride in double distilled water. One $\mathrm{ml}$ of concentrated $\mathrm{HCl}$ was added to the stock solution to avoid further hydrolysis. Distilled kerosene was used as organic phase diluent. Organic phase solution was prepared by dissolving the required amount of the extractants in kerosene and then diluting to the required concentration except for diluent variation experiment. The commercial extractant, tri-octyl amine (TOA) (Merck), Cyanex 923, obtained from Cytec Inc. Canada, were 
used without further purification. All other reagents used were of analytical reagent grade.

\subsection{Experimental Procedure}

The extraction process deals with the distribution of a solute between two immiscible solvents in equal aliquots (10 ml), one of which is aqueous and the other an organic solvent. The aqueous phase containing $\mathrm{ZrOCl}_{2}$ solution $(0.001 \mathrm{M})$ in $\mathrm{HCl}$ and the organic phase with TOA and Cyanex 923 in kerosene were shaken in a separating funnel for about twenty five minutes. Then the phases were allowed to settle for five minutes and then they were separated. The zirconium (IV) concentration in the aqueous phase before and after the extraction was determined by Arsenazo (III) method using an ELICO UV-Visible spectrophotometer. The distribution coefficient was calculated by taking the ratio of equilibrium concentration of zirconium (IV) in organic phase and that in the aqueous phase. The concentration of $\operatorname{Zr}(\mathrm{IV})$ in the organic phase was calculated by using the mass balance i.e., the difference of metal concentration in the aqueous phase before and after the extraction. From $\mathrm{D}$ value, the percentage of extraction was calculated $(\% \mathrm{E}=100(\mathrm{D} / \mathrm{D}+1)$. Stripping percentage was calculated by using the relation, \% stripping $=\left[[\mathrm{Zr}]_{s} /\left([\mathrm{Zr}]_{0}-[\mathrm{Zr}]\right)\right] \times 100$, where $[\mathrm{Zr}]_{0}$ is the original $\mathrm{Zr}$ (IV) concentration in the aqueous phase before extraction, $[\mathrm{Zr}]$ is the $\mathrm{Zr}(\mathrm{IV})$ concentration in the aqueous phase after extraction and $[\mathrm{Zr}]_{\mathrm{s}}$ is the $\mathrm{Zr}(\mathrm{IV})$ concentration in the aqueous phase after stripping.

\section{Results and Discussion}

\subsection{Effect of Acid and Extractant Concentration}

The extraction of $0.001 \mathrm{M} \mathrm{Zr}$ (IV) from $3 \mathrm{M}$ to $7 \mathrm{M} \mathrm{HCl}$ was studied with the binary mixture of $0.1 \mathrm{M}$ TOA and 0.01 M Cyanex 923 in kerosene. The percentage of extraction of $\mathrm{Zr}$ (IV) increased from 15.5\% to 100\% with increase in acid concentration from $3 \mathrm{M}$ to $7 \mathrm{M} \mathrm{HCl}$ with mixture of $0.1 \mathrm{M}$ TOA and $0.01 \mathrm{M}$ Cyanex 923 in kerosene and the results are shown in Figure 1. This may be attributed to the better efficiency of mixture in extracting $\mathrm{Zr}(\mathrm{IV})$ at higher acid concentration.

Experiments were carried out with constant level of Cyanex 923(0.01 M) in the presence of varying concentration of TOA in the range of $0.1 \mathrm{M}-1 \mathrm{M}$ from $4 \mathrm{M} \mathrm{HCl}$ and $5 \mathrm{M} \mathrm{HCl}$. It was observed that the extent of extraction decreases from $58.2 \%$ to $6.4 \%$ and $75.5 \%$ to $7.0 \%$ from $4 \mathrm{M} \mathrm{HCl}$ and $5 \mathrm{M} \mathrm{HCl}$ respectively with increasing TOA concentration from $0.1 \mathrm{M}$ to $1.0 \mathrm{M}$. It may be due to interaction between TOA and the neutral extractant, Cyanex 923 at higher molarity, leading to antagonistic effect described in Figure 2.

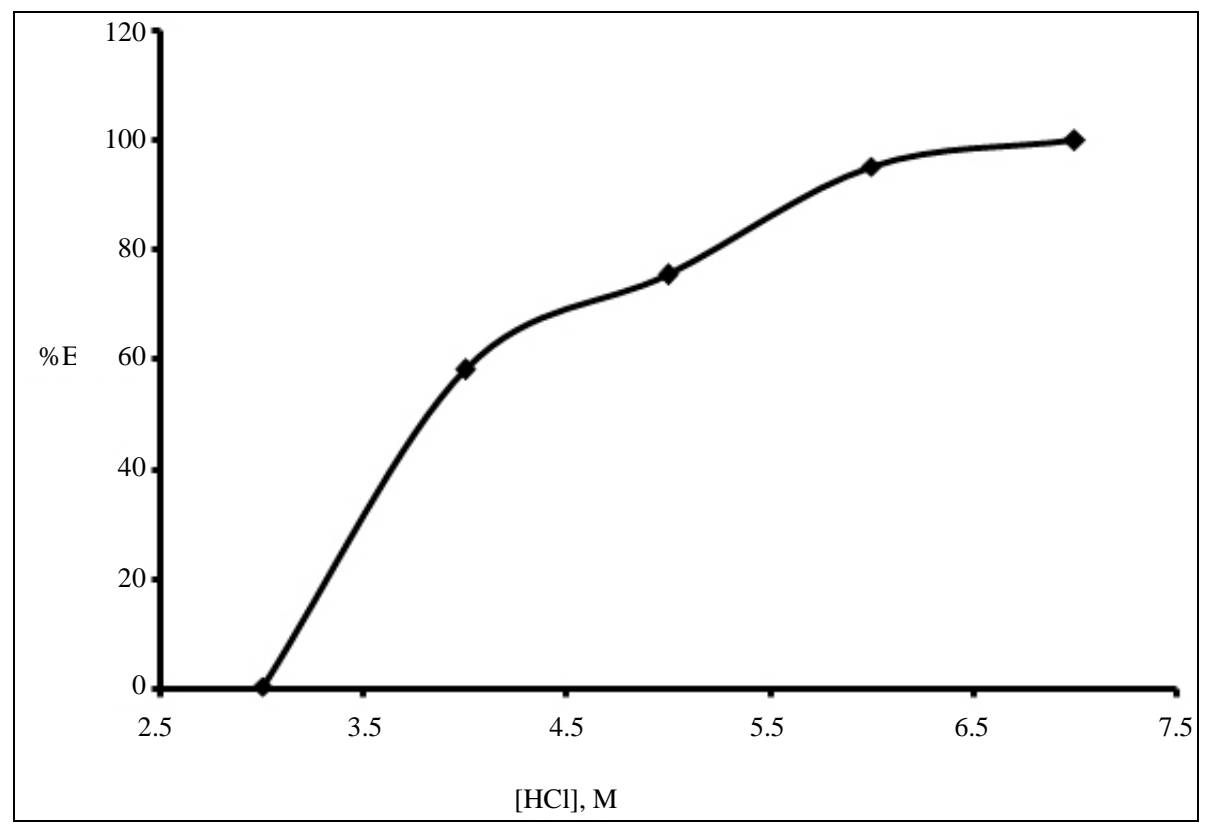

Figure 1. Effect of hydrochloric acid concentration on the percentage of extraction of 0.001 M Zr (IV) using mixture of 0.1 M TOA and 0.01 M Cyanex 923. 


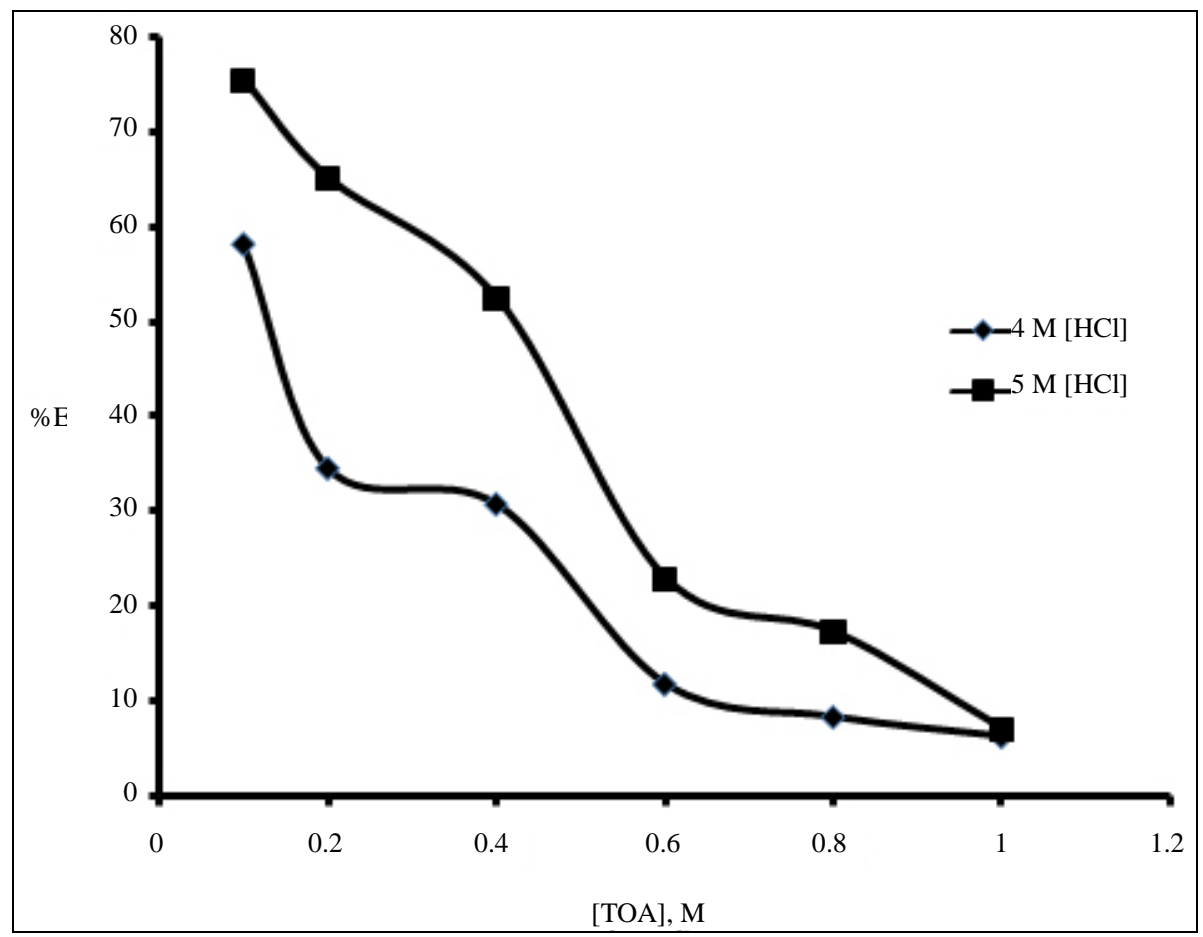

Figure 2. Plot of \%E versus [TOA], $\mathrm{M}$ in the extraction of $0.001 \mathrm{M} \mathrm{Zr}$ (IV) using mixture of TOA (varied) and $0.01 \mathrm{M}$ Cyanex 923 (4 M and $5 \mathrm{M} \mathrm{HCl}$ ).

The effect of Cyanex 923 at fixed TOA concentration $(0.1 \mathrm{M})$ on the extraction of $0.001 \mathrm{M} \mathrm{Zr(IV)}$ from $4 \mathrm{M}$ $\mathrm{HCl}$ was studied by varying Cyanex 923 concentration from $0.002 \mathrm{M}$ to $0.1 \mathrm{M}$. It was found that extraction increased from $7.5 \%$ to $100 \%$ with the increase in concentration from $0.002 \mathrm{M}$ to $0.02 \mathrm{M}$ of Cyanex 923 and then remained constant at $100 \%$ when the extractant molarity increased from 0.02 to $0.1 \mathrm{M}$. The plot of $\log \mathrm{D}_{\text {mix }}$ versus $\log$ [Cyanex 923] yields a slope of 1.6 given in Figure 3 showing incorporation of two molecules of Cyanex 923 in the extracted species. The increase in extraction is due to the formation of more hydrophobic species replacing the water molecules of hydration from the co-ordination sphere of the metal.

\subsection{Effect of Chloride Ion Concentration}

The effect of chloride ion on the binary extraction system was studied by adding varying concentrations of $\mathrm{NaCl}$ $(0.01 \mathrm{M}-0.08 \mathrm{M}), \mathrm{NH}_{4} \mathrm{Cl}(0.01 \mathrm{M}-0.1 \mathrm{M}), \mathrm{KCl}(0.01 \mathrm{M}-0.1 \mathrm{M})$ to the aqueous phase containing $0.001 \mathrm{M} \mathrm{Zr}$ (IV) and $4 \mathrm{M} \mathrm{HCl}$. With binary mixture of $0.1 \mathrm{M}$ TOA and $0.01 \mathrm{M}$ Cyanex 923 as extractant in kerosene the percentage of extraction increased from $47.2 \%$ to $85.2 \%$ when the concentration of $\mathrm{NaCl}$ increased from $0.01 \mathrm{M}$ - $0.08 \mathrm{M}$, from $29.3 \%$ to $81.4 \%$ when the concentration of $\mathrm{NH}_{4} \mathrm{Cl}$ increased from $0.01 \mathrm{M}-0.1 \mathrm{M}$ and from $22 \%$ to $67.9 \%$ when the concentration of $\mathrm{KCl}$ increased from $0.01 \mathrm{M}-0.1 \mathrm{M}$ indicating the involvement of chloride ions in the extraction as shown in Figure 4.

\subsection{Effect of Metal Ion Concentration}

To know the effect of metal ion concentration on the binary extraction system, varying concentrations of $\mathrm{Zr}(\mathrm{IV})$ from $0.001 \mathrm{M}-0.02 \mathrm{M}$, in the aqueous phase in $4 \mathrm{M} \mathrm{HCl}$ was equilibrated with binary mixture of $0.1 \mathrm{M}$ TOA and $0.01 \mathrm{M}$ Cyanex 923 in kerosene. The percentage of extraction increased from 58.3\% to 86\%. The plot of \%E versus [Metal], $\mathrm{M}$ indicates increase in extraction increasing with increasing concentration of metal ion Figure 5.

\subsection{Effect of Diverse Ion}

The effect of diverse ions such as Fe (III) and $\mathrm{Al}$ (III) ion on the extraction of $\mathrm{Zr}$ (IV) from $4 \mathrm{M} \mathrm{HCl}$ using mixture 


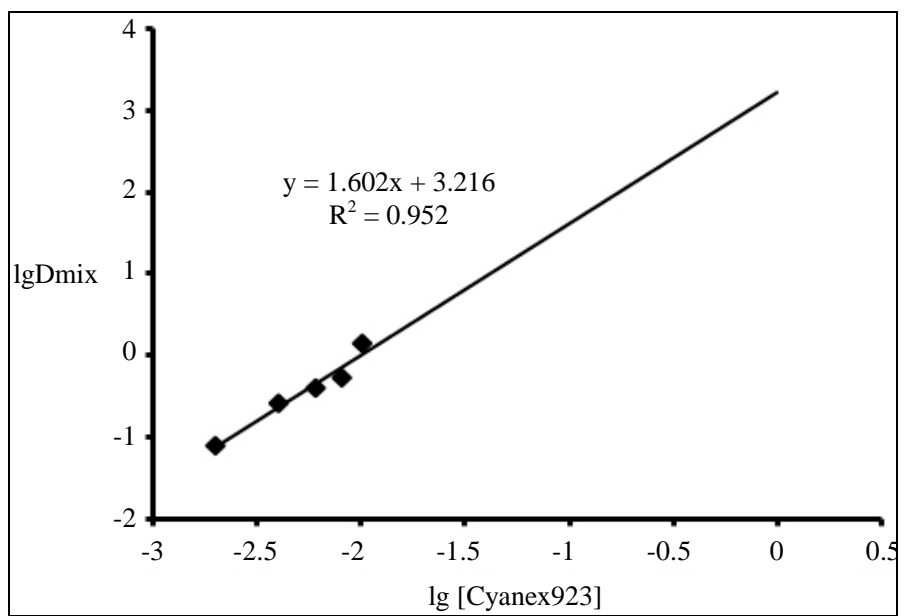

Figure 3. Plot of log Dmix versus log [Cyanex 923] in the extraction of $0.001 \mathrm{M} \mathrm{Zr}$ (IV) from $4 \mathrm{M} \mathrm{HCl}$ using binary mixture of $0.1 \mathrm{M}$ TOA and Cyanex 923 (varied).

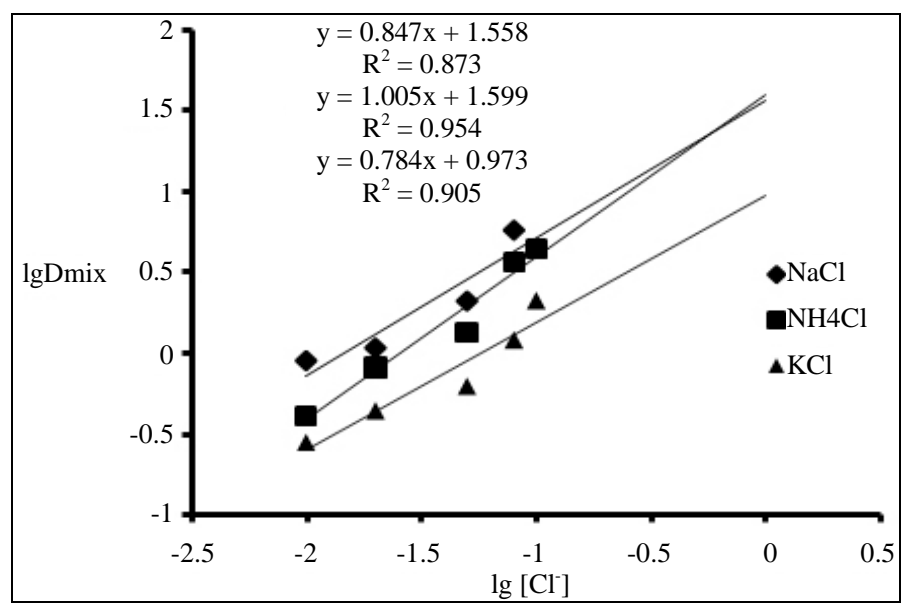

Figure 4. Effect of chloride ion concentration on the extraction of $0.001 \mathrm{M} \mathrm{Zr}$ (IV) from $4 \mathrm{M} \mathrm{HCl}$ using binary mixture of $0.1 \mathrm{M}$ TOA and 0.01 M Cyanex 923.

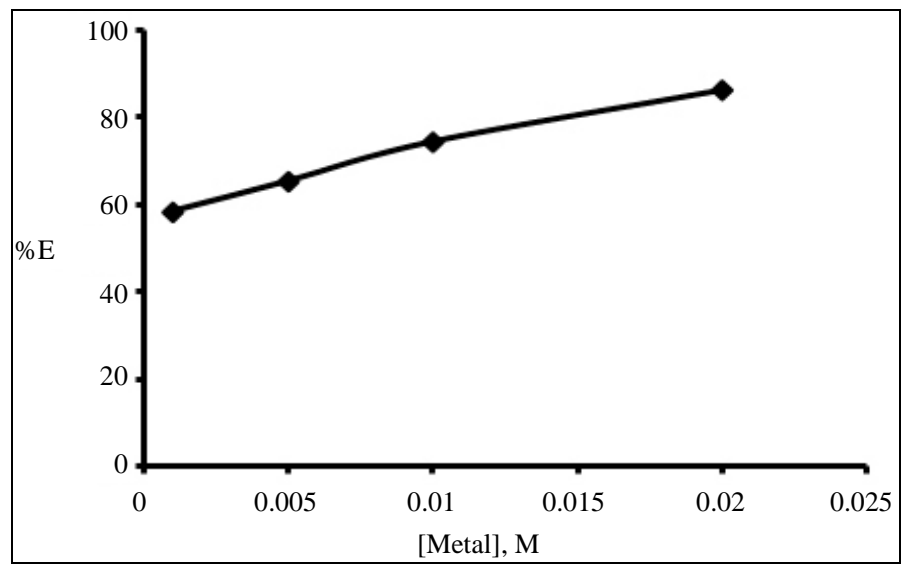

Figure 5. Effect of metal ion concentration on the extraction of $\mathrm{Zr}$ (IV) from $4 \mathrm{M} \mathrm{HCl}$ using binary mixture of $0.1 \mathrm{M}$ TOA and $0.01 \mathrm{M}$ Cyanex 923 . 
of 0.1 M TOA and 0.01 M Cyanex 923 in kerosene has been investigated. When Fe (III) and Al (III) ions are added to the extraction system, there is a decrease in distribution coefficient of Zirconium (IV) as shown in Table 1. This may be due to the competition between two metal ions present in the system for the extractant.

\subsection{Effect of Diluents}

Extraction experiments were carried out using various diluents (Kerosene, Benzene, Toluene, Chloroform and Xylene) for the extraction of $0.001 \mathrm{M} \mathrm{Zr}$ (IV) from $4 \mathrm{M} \mathrm{HCl}$ with binary mixture of $0.1 \mathrm{M}$ TOA and $0.01 \mathrm{M}$ Cyanex 923 as extractants. It was observed that the percentage of extraction was maximum with the binary mixture prepared in benzene, as diluents Table 2. Due to low toxicity and easy availability, kerosene was chosen as the diluent for the study.

\subsection{Effect of Temperature}

The effect of temperature on the extraction of $0.001 \mathrm{M} \mathrm{Zr}$ (IV) from aqueous solution containing $4 \mathrm{M} \mathrm{HCl}$ using binary mixture of $0.1 \mathrm{M}$ TOA and $0.01 \mathrm{M}$ Cyanex 923 in kerosene was studied in the temperature range $298 \mathrm{~K}$ $339 \mathrm{~K}$. It was observed that an increase in temperature of the extracting solution caused an increase in the extraction. The extraction of $\mathrm{Zr}$ (IV) increased from $58.2 \%$ at $298 \mathrm{~K}$ to $100 \%$ at $339 \mathrm{~K}$. The results showed in Figure 6 as plot of log K versus 1000/T gives a linear relation with a negative slope. Applying Van't Hoffs equation the thermodynamic parameters, $\Delta \mathrm{H}^{0}$ and $\Delta \mathrm{S}^{0}$ were calculated to be $51.0 \mathrm{~kJ} \cdot \mathrm{mol}^{-1}$ and $229.7 \mathrm{JK}^{-1} \cdot \mathrm{mol}^{-1}$, respectively. It ensures the extraction process to be endothermic accompanying with an increase in the randomness as a result of release of water molecules of hydration from the coordination sphere of the metal in case of binary extraction system.

\subsection{Stripping}

The loaded organic phase is stripped off the metal by the back extraction to the aqueous phase which is required

Table 1. Effect of Fe(III) and $\mathrm{Al}(\mathrm{III})$ ions on the extraction of $0.001 \mathrm{M} \mathrm{Zr(IV)} \mathrm{from} 4 \mathrm{M} \mathrm{HCl}$ with mixture of $0.1 \mathrm{M}$ TOA and $0.01 \mathrm{M}$ Cyanex 923 in kerosene. (\% extraction of $\mathrm{Zr}$ (IV) in absence of diverse ions = $58.2 \%)$.

\begin{tabular}{cccc}
\hline Sl. No. & Diverse ions & Concentration of diverse ions, $\mathrm{M}$ & \%Extraction of $\mathrm{Zr}(\mathrm{IV})$ \\
\hline \multirow{3}{*}{1} & & 0.0005 & 24.5 \\
& & 0.001 & 33.7 \\
& & 0.005 & 42.6 \\
& & 0.01 & 56.5 \\
& & 0.0005 & 29.2 \\
& \multirow{2}{*}{$\mathrm{Al}(\mathrm{III})$} & 0.001 & 49.2 \\
& & 0.005 & 55.4 \\
& & 0.01 & 71.6 \\
\hline
\end{tabular}

Table 2. Effect of diluents on the extraction of $0.001 \mathrm{M} \mathrm{Zr(IV)} \mathrm{from} 4 \mathrm{M} \mathrm{HCl}$ with mixture of $0.1 \mathrm{M}$ TOA and 0.01 M Cyanex 923.

\begin{tabular}{ccc}
\hline Diluents & $\mathrm{D}_{\text {mix }}$ & $\% \mathrm{E}$ \\
\hline Benzene & 253.33 & 99.6 \\
Toluene & 23.61 & 95.9 \\
Xylene & 0.032 & 3.1 \\
Chloroform & 6.596 & 86.8 \\
Kerosene & 1.391 & 58.2 \\
\hline
\end{tabular}


for commercial extraction processes. Regeneration of the solvent is achieved by treating the solvent with alkali or acid solutions. The effect of various concentrations of strippants on the stripping of metal ions from the loaded organic solvent was studied at $25^{\circ} \mathrm{C}$ and phase ratio 1:1. Zirconium was stripped from loaded organic phase of TOA $(0.1 \mathrm{M})$ and Cyanex $923(0.01 \mathrm{M})$ containing $91.22 \mathrm{mg} / \mathrm{L}$ of zirconium with various stripping agents such as $\mathrm{Na}_{2} \mathrm{CO}_{3}(0.01 \mathrm{M}-0.5 \mathrm{M})$ and $\mathrm{HNO}_{3}(0.05-1.25 \mathrm{M})$. Stripping of $\mathrm{Zr}(\mathrm{IV})$ was $100 \%$ with $0.05 \mathrm{M} \mathrm{HNO}_{3}$ and with $0.5 \mathrm{M} \mathrm{Na}_{2} \mathrm{CO}_{3}$ in one step. The basic stripping agent like $\mathrm{Na}_{2} \mathrm{CO}_{3}$ and low acid concentration compared to that taken for extraction deprotonate the amine salt and in turn helps in increase in stripping. The stripping percentage with various strippants is listed in Table 3.

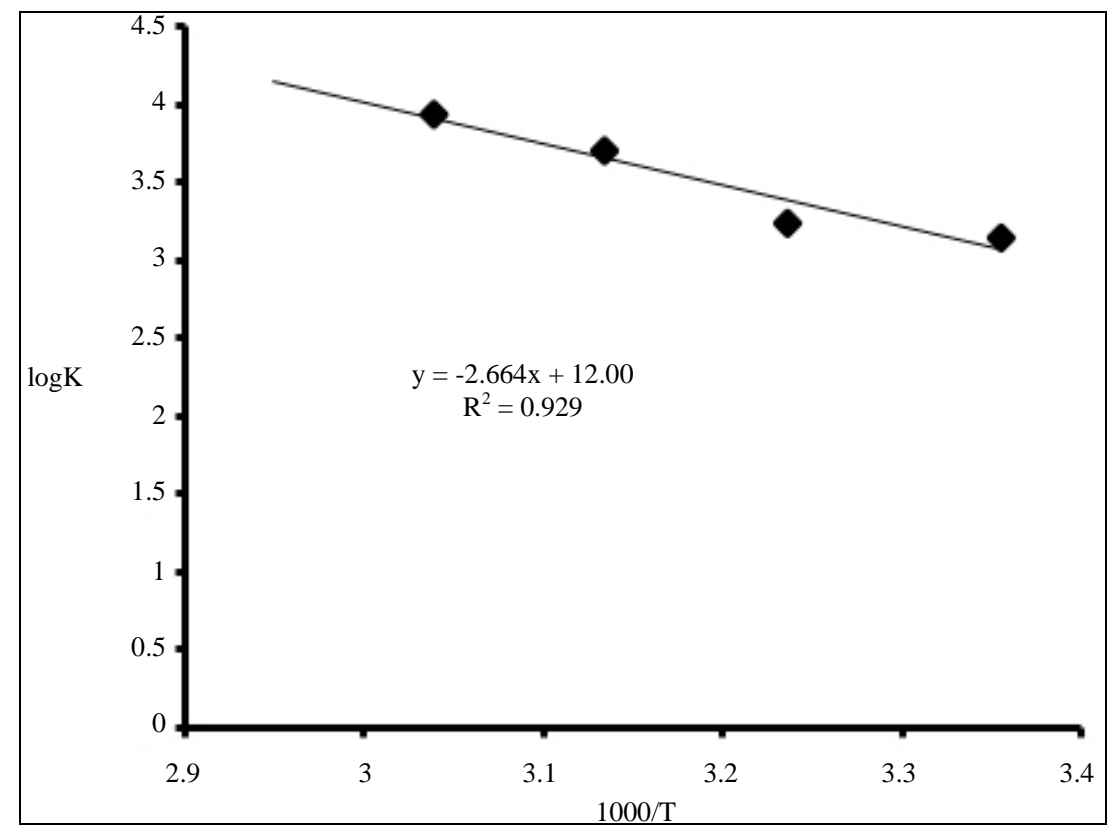

Figure 6. Plot of log K versus 1000/T for extraction of $0.001 \mathrm{M} \mathrm{Zr}$ (IV) from $4 \mathrm{M}$ $\mathrm{HCl}$ using binary mixture of $0.1 \mathrm{M}$ TOA and $0.01 \mathrm{M}$ Cyanex 923 in kerosene.

Table 3. Stripping of Zr(IV) from loaded organic phase containing mixture of $0.1 \mathrm{M}$ TOA and $0.01 \mathrm{M}$ Cyanex 923.

\begin{tabular}{|c|c|c|c|}
\hline Sl.No. & Name of the Strippant & [Stripant], M & \%Stripping \\
\hline \multirow{7}{*}{1} & \multirow{7}{*}[\mathrm{HNO}_{3}]{} & 1.25 & 72.7 \\
\hline & & 1.0 & 81.9 \\
\hline & & 0.8 & 84.6 \\
\hline & & 0.5 & 87.3 \\
\hline & & 0.1 & 88.6 \\
\hline & & 0.08 & 96.0 \\
\hline & & 0.05 & 100 \\
\hline \multirow{8}{*}{2} & \multirow{8}{*}[\mathrm{Na}_{2}\mathrm{CO}_{3}]{} & 0.01 & 28.5 \\
\hline & & 0.02 & 46.2 \\
\hline & & 0.04 & 49.9 \\
\hline & & 0.06 & 55.9 \\
\hline & & 0.08 & 60.0 \\
\hline & & 0.1 & 66.5 \\
\hline & & 0.2 & 78.9 \\
\hline & & 0.5 & 100 \\
\hline
\end{tabular}




\section{Conclusion}

The present investigation shows that the extraction of zirconium (IV) from $\mathrm{HCl}$ medium with mixture of TOA and Cyanex 923 is more than that with only TOA but less than that with only Cyanex 923 (up to $6 \mathrm{M} \mathrm{HCl}$ ) whereas at higher acid molarity (7 M) synergism is obtained in the extraction. Quantitative extraction (100\%) is observed from the aqueous phase containing $0.001 \mathrm{M} \mathrm{Zr}$ (IV) and $7 \mathrm{M} \mathrm{HCl}$ with binary mixture of $0.1 \mathrm{M}$ TOA and $0.01 \mathrm{M}$ Cyanex 923 in kerosene. Benzene is proved to be an effective diluent for the binary extraction system. An increase in temperature has a positive influence on the extraction process. Stripping is best carried out with $0.05 \mathrm{M} \mathrm{HNO}_{3}$ and $0.5 \mathrm{M} \mathrm{Na}_{2} \mathrm{CO}_{3}$.

\section{Acknowledgements}

The authors are thankful to Cytec Inc., Canada for providing the gift sample of Cyanex 923. The authors express their sincere thanks to authorities of Siksha' $O$ ' Anusandhan deemed to be University for their constant encouragement for research and to Dr. S. K. Sahu, NML, Jamsedpur, for his suggestions. One of the authors (B. C. Bhatta) is grateful to authorities of College of Engineering and Technology, Bhubaneswar for granting permission to do the research work.

\section{References}

[1] Kirk-Othmer (2001) Encyclopedia of Chemical Technology. 5th Edition, John Wiley \& Sons, 621-663.

[2] Das, N.R. and Lahiri, S. (1994) Liquid-Liquid Extraction of Trace Level Zirconium and Hafnium with Trioctylamine. Journal of Radioanalytical and Nuclear Chemistry, 181, 157-164. http://dx.doi.org/10.1007/BF02037556

[3] Cerrai, E. and Testa, C. (1959) Extraction and Separation of Zirconium and Hafnium by Means of Liquid Anionic Exchangers in a Hydrochloric Acid Medium. I. Behavior of Some Primary, Secondary, and Tertiary Amines. Energy and Nuclear, 6, 707-716.

[4] El-Yamani, I.S., Farah, M.Y. and Abd El-Aleim, F.A. (1978) Studies on Extraction of Zirconium by Quaternary Ammonium Halides from Hydrochloric Acid Media and Its Separation from Hafnium. Talanta, 25, 714-716. http://dx.doi.org/10.1016/0039-9140(78)80183-0

[5] Karve, M.A. and Khopkar, S.M. (1992) Application of Liquid Anion Exchangers for the Separation of Zirconium and Hafnium. Analytical Sciences, 8, 237-241. http://dx.doi.org/10.2116/analsci.8.237

[6] Poriel, L., Favre-Reguillon, A., Pellet-Rostaing, M.S.L. (2006) Zirconium and Hafnium Separation, Part 1. Liquid/Liquid Extraction in Hydrochloric Acid Aqueous Solution with Aliquat 336. Separation Science and Technology, 41, 1927-1940. http://dx.doi.org/10.1080/01496390600725802

[7] Abdel-Fattah, A.A., Ali, S.M. and EI-Sweify, F.H. (2002) Thermodynamics of the Solvent Extraction of Zr(IV) by Amberlite LA-2,TBP and HDEHP from Different Aqueous Media. Journal of Radioanalytical and Nuclear Chemistry, 253, 465-475. http://dx.doi.org/10.1023/A:1020433906562

[8] Reddy, B.R., Kumar, J.R., Reddy, A.V. and Priya, D.N. (2004) Solvent Extraction of Zirconium (IV) from Acidic Chloride Solutions Using 2-Ethyl Hexyl Phosphonic Acid Mono-2-Ethyl Hexyl Ester (PC-88A). Hydrometallurgy, 72, 303-307. http://dx.doi.org/10.1016/j.hydromet.2003.07.002

[9] Reddy, B.R., Kumar, J.R. and Reddy, A.V. (2004) Liquid-Liquid Extraction of Tetravalent Zirconium from Acidic Chloride Solutions Using Cyanex 272. Analytical Sciences, 20, 501-505. http://dx.doi.org/10.2116/analsci.20.501

[10] Pershina, V., Trubert, D., Naour, C.L. and Kratz, J.V. (2002) Theoretical Predictions of Hydrolysis and Complex Formation of Group-4 Elements Zr, Hf and Rf in HF and HCl Solutions. Radiochim Acta, 90, 869-877. http://dx.doi.org/10.1524/ract.2002.90.12_2002.869

[11] Lee, H.Y., Kim, S.G. and Oh, J.K. (2004) Stoichiometric Relation for Extraction of Zirconium and Hafnium from Acidic Chloride Solutions with Versatic Acid 10. Hydrometallurgy, 73, 91-97.

http://dx.doi.org/10.1016/j.hydromet.2003.08.004

[12] Chang, C.C., Chiu, T.M., Hoh, Y.C. and Wang, W.K. (1986) Separation of Iron from Zirconium in Concentrated Hydrochloric Acid Solutions by Solvent Extraction. Hydrometallurgy, 17, 1-13. http://dx.doi.org/10.1016/0304-386X(86)90016-2

[13] Blake, C.A., et al. (1958) Solvent Extraction of Uranium and Other Metals by Acidic and Neutral Organophosphorus Compounds. Proceedings of the 2nd United Nations International Conference on the Peaceful Uses of Atomic Energy, Geneva, 1-13 September 1958, 289-298.

[14] Mathur, J.N. (1983) Synergism of Trivalent Actinides and Lanthanides. Solvent Extraction and Ion Exchange Spectro- 
chim, 1, 349-412. http://dx.doi.org/10.1080/07366298308918406

[15] Banerjee, S. and Basu, S. (2004) Synergistic Effect of Neutral Donors on the Extraction of Zirconium (IV) by Salicylaldoxime in Dichloromethane. Journal of Radioanalytical and Nuclear Chemistry, 262, 733-737. http://dx.doi.org/10.1007/s10967-004-0501-z

[16] Biswas, S. and Basu, S. (1999) Extraction of Zirconium (IV) from Hydrochloric Acid Solutions by Tri-Octylamine and Neutral Donors. Journal of Radioanalytical and Nuclear Chemistry, 242, 253-258. http://dx.doi.org/10.1007/BF02345549

[17] Reddy, A.S. and Reddy, B.R. (1978) Synergistic Solvent Extraction of Zirconium (IV) Effect of Di-n-pentyl Sulfoxide on the Kinetic Extraction of Zr(IV) with 2-Thenoyltrifluoroacetone. Journal of Radioanalytical Chemistry, 47, 77-82. http://dx.doi.org/10.1007/BF02517156

[18] Mishra, P.K., Chakravortty, V., Dash, K.C. and Bhattacharyya, S.N. (1992) Extraction and Separation of Zirconium, Niobium, and Hafnium by Aliquat 336 and Its Mixtures with Tri-n-octyl phosphine Oxide (TOPO) from Acidic Thiocyanate Media. Journal of Radioanalytical and Nuclear Chemistry, 162, 289-298. http://dx.doi.org/10.1007/BF02035390

[19] Taghizadeh, M., Ghandhi, M. and Zolfonoun, E. (2011) Separation of Zirconium and Hafnium by Solvent Extraction Using Mixture of TBP and Cyanex 923. Journal of Nuclear Materials, 412, 334-337.

http://dx.doi.org/10.1016/j.jnucmat.2011.03.033

[20] Bhatta, B.C., Panda, N. and Mishra, S. (2013) Liquid Liquid Extraction of Zr(IV) from Hydrochloric Acid Using TOA and Cyanex 921 in Kerosene. International Journal of Minerals, Metallurgy and Materials, 20, 823-828. http://dx.doi.org/10.1007/s12613-013-0802-8 